\title{
Impact of human papillomavirus infection on semen parameters and reproductive outcomes
}

\author{
Hana Jaworek1', Vladimira Koudelakova ${ }^{1 *}$ (D) Ivana Oborna ${ }^{2,3^{*}}$, Blazena Zborilova ${ }^{2}$, Jana Brezinova ${ }^{3}$, \\ Dagmar Ruzickova ${ }^{4}$, Jana Vrbkova', Pavla Kourilova ${ }^{1}$ and Marian Hajduch ${ }^{1}$
}

\begin{abstract}
Background: Human papillomavirus (HPV) has been shown to adversely affect human reproduction. We aimed to evaluate the prevalence of human papillomavirus (HPV) infection in men and its correlation with semen parameters and reproductive outcomes.

Methods: Semen samples and penile swabs were collected from potential sperm donors $(S D, n=97)$ and male partners of infertile couples (IM, $n=328)$. The presence of HPV DNA in semen samples and penile swabs was analyzed. Associations between hrHPV positive status and fertility outcomes as well as socio-behavioral and health characteristics were evaluated using the R software package.

Results: High-risk HPV (hrHPV) genotypes were detected in $28.9 \%$ of SD and $35.1 \%$ of IM ( $P=0.312$ ). Penile swabs were more frequently positive for hrHPV genotypes than semen samples in both IM $(32.3 \% \mathrm{vs} .11 .9 \%, P<0.001)$ and SD $(26.8 \%$ vs. $6.2 \%, P=0.006)$.

Men with hrHPV positive semen samples had lower semen volume (median volume $2.5 \mathrm{ml}$ vs. $3 \mathrm{ml}, P=0.009$ ), sperm concentration (median concentration $16 \times 10^{6} / \mathrm{ml}$ vs. $31 \times 10^{6} / \mathrm{ml}, P=0.009$ ) and total sperm count (median count $46 \times 10^{6}$ vs. $82 \times 10^{6}, P=0.009$ ) than men with hrHPV negative samples. No association was identified between penile hrHPV status and semen parameters.
\end{abstract}

Conclusions: Our findings indicate that penile HPV infection is common in both potential sperm donors and men from infertile couples. Although HPV positivity is higher in penile swabs, only HPV infection in semen samples affects sperm parameters. However, there was no association between hrHPV positivity in semen and fertility outcomes including abortion rate.

Keywords: Human papillomavirus, Semen, Penile swab, Infertility, Sperm donor

*Correspondence: vladimira.koudelakova@upol.cz; obornai@seznam.cz ${ }^{1}$ Institute of Molecular and Translational Medicine, Faculty of Medicine and Dentistry, Palacky University Olomouc, Hnevotinska 1333/5, 779 00 Olomouc, Czech Republic

${ }^{2}$ Fertimed Ltd., Boleslavova 2, 77600 Olomouc, Czech Republic

Full list of author information is available at the end of the article

\begin{abstract}
Background
Human papillomaviruses (HPVs) are the causative agents of a common sexually transmitted disease that preferentially infects squamous epithelial cells [1] and are also an important factor in carcinogenesis in both men and women [2, 3]. Many studies have focused on HPV-associated diseases in women, but there is comparatively little data on male infection. The estimated prevalence of HPV infection in males ranges from 1.3 to $72.9 \%$ depending
\end{abstract} original author(s) and the source, provide a link to the Creative Commons licence, and indicate if changes were made. The images or other third party material in this article are included in the article's Creative Commons licence, unless indicated otherwise in a credit line to the material. If material is not included in the article's Creative Commons licence and your intended use is not permitted by statutory regulation or exceeds the permitted use, you will need to obtain permission directly from the copyright holder. To view a copy of this licence, visit http://creativecommons.org/licenses/by/4.0/. The Creative Commons Public Domain Dedication waiver (http://creativeco mmons.org/publicdomain/zero/1.0/) applies to the data made available in this article, unless otherwise stated in a credit line to the data. 


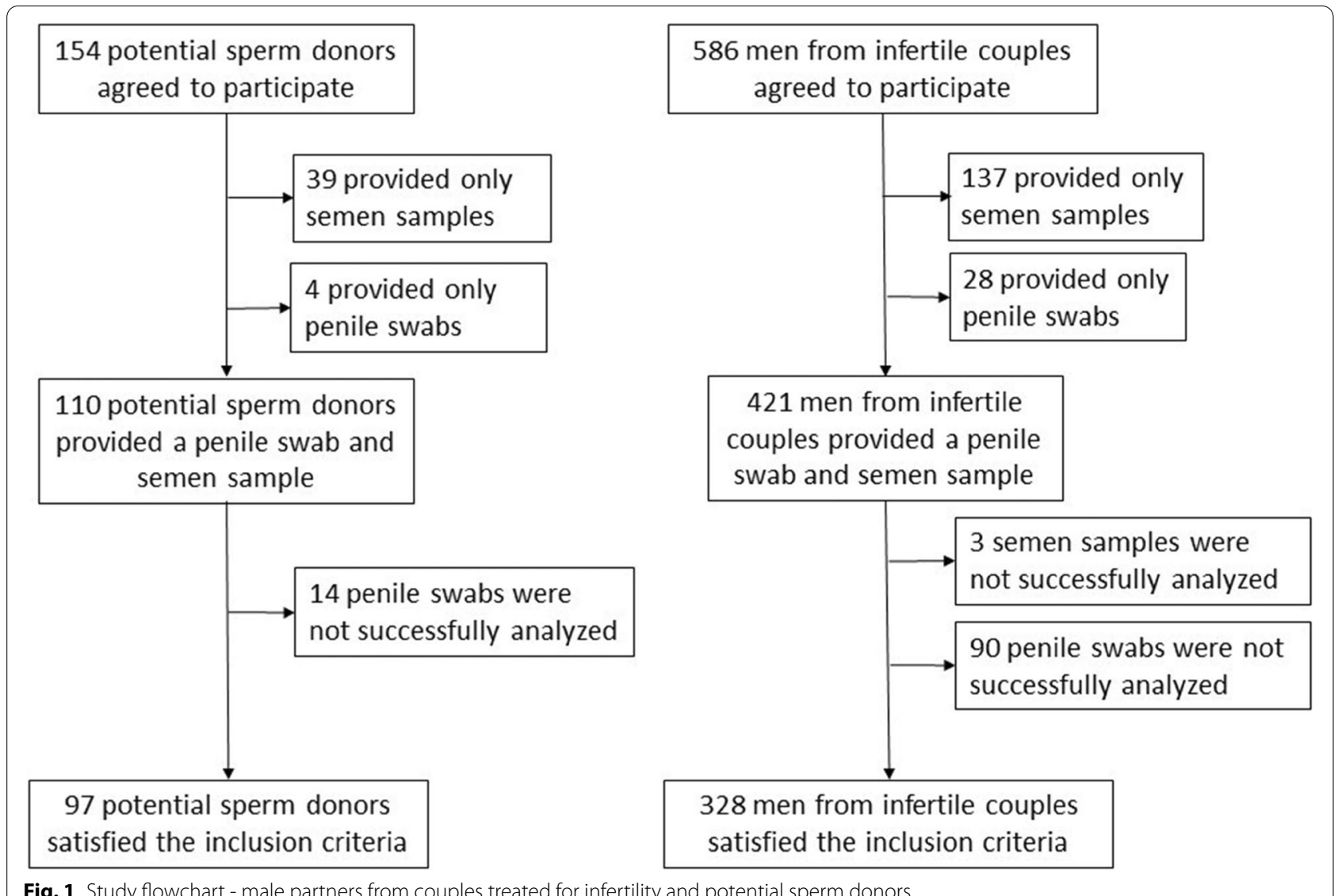

Fig. 1 Study flowchart - male partners from couples treated for infertility and potential sperm donors

on the anatomic site of specimen collection and testing method $[4,5]$. While male HPV infections may be associated with lower mortality and morbidity than HPV infections in women, they still warrant investigation due to their association with genital warts, penile, anal, and oropharyngeal cancer, and the high risk of transmission to sexual partners $[6,7]$.

HPV can be found along the entire male and female genital tract as well as in semen, where it binds to the sperm head and significantly reduces sperm motility [5, 8]. Moreover, Foresta et al. showed that HPV infected spermatozoa can penetrate the oocyte [9], and multiple in vitro studies have indicated that HPV can adversely affect early embryonic development [10-12]. Consequently, there is growing interest in the impact of HPV on male fertility. Several studies have shown that HPV infection can negatively influence pregnancy rates during assisted reproduction treatment (ART) and increase abortion rates in both spontaneous pregnancies and pregnancies after ART [13-15].

In this study we investigated the prevalence of HPV in semen samples and penile swabs from potential sperm donors (SD) and male partners from couples treated for infertility (IM), and its impact on semen parameters and fertility outcomes.

\section{Methods}

\section{Study design and inclusion criteria}

Individuals considered eligible to participate in the first part of the study were male partners from couples treated for infertility and potential sperm donors who provided both semen samples and penile swabs (Fig. 1). For the second part of the study, where fertility outcomes were evaluated, we included couples treated for infertility who provided both a semen sample and a cervical swab (Fig. 2). All samples were collected between July 2013 and November 2016 together with other samplings. Samples were collected at two Czech fertility centers (Fertimed Ltd., Olomouc and Arleta IVF Ltd., Kostelec nad Orlici) and at SpermBank International Ltd., Olomouc, which operate in the same region. The demographic characteristics of tested subjects were considered comparable.

Inclusion criteria for men from infertile couples were: duration of infertility greater than 1 year and infertility due to various causes. Inclusion criteria for women from 


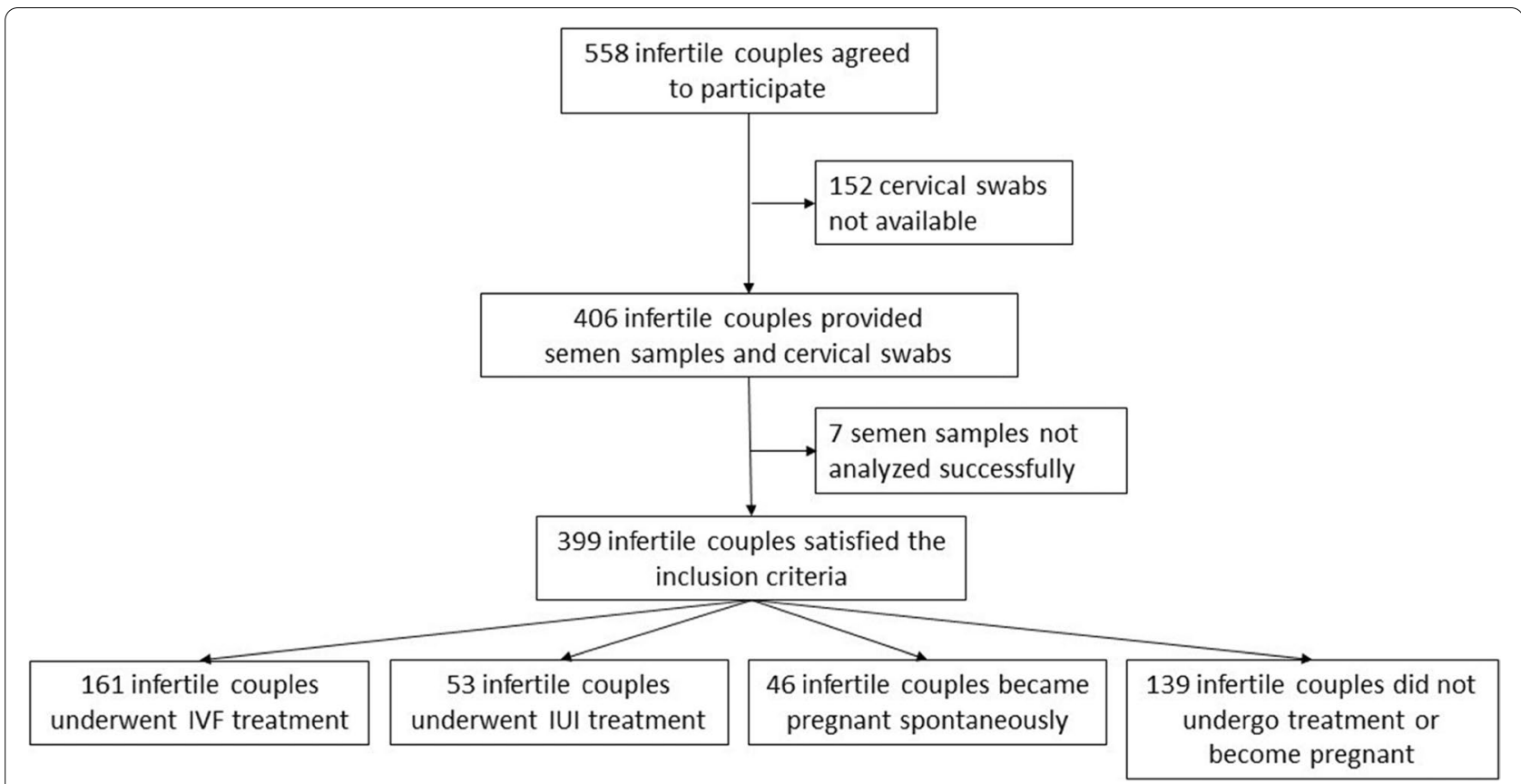

Fig. 2 Study flowchart - couples treated for infertility

infertile couples were: duration of infertility greater than 1 year, infertility due to various causes, and age between 18 and 49 years.

Potential sperm donors were tested according to the criteria specified in the European Commission Directive 2004/23/ES and the Czech Directive 296/2008. HPV testing was performed simultaneously.

\section{Collection of semen samples and penile swabs from potential sperm donors}

Penile swabs and semen samples were collected from a cohort of $328 \mathrm{IM}$ and 97 potential SD (Fig. 1). Participants self-collected penile swab samples by wiping a dry cotton swab at least three times around the coronal sulcus and the top of the glans. Each swab was then rinsed in $0.5 \mathrm{ml}$ of cobas ${ }^{\circledR}$ PCR Cell Collection Media (Roche Diagnostics GmBH, Mannheim, Germany). Semen samples were subsequently obtained by masturbation after 3 to 5 days of sexual abstinence. After liquefaction of the ejaculate at room temperature, at least $0.1 \mathrm{ml}$ of ejaculate was placed in $20 \mathrm{ml}$ of cobas $^{\circledR}$ PCR Cell Collection Media (Roche Diagnostics GmBH, Mannheim, Germany). The media were transported and stored at room temperature until testing according to the manufacturer's recommendations for cervical samples. Semen analysis (volume, $\mathrm{pH}$, viscosity, sperm concentration, motility, and normal morphology) was performed according to World Health Organization guidelines [16].

\section{Collection of cervical swabs and semen samples from couples treated for infertility}

Cervical swabs and semen samples were collected from 399 female and male partners treated for infertility (Fig. 2). Cervical swabs were taken from women before planned intrauterine insemination (IUI), in vitro fertilization (IVF) or intracytoplasmic injection (ICSI) treatment. Cervical brushes were rinsed in $20 \mathrm{ml}$ of cobas ${ }^{\circledR}$ PCR Cell Collection Media (Roche Diagnostics GmBH, Mannheim, Germany) and transported and stored at room temperature according to the manufacturer's recommendations for cervical samples. Semen samples were obtained as described above.

For infertility treatment, spermatozoa were separated either by swim-up or density gradient techniques and used in either IUI, IVF or IVF + ICSI techniques. The number of pregnancies (gestational sac and fetal heart beats proven by ultrasound within weeks six to nine of pregnancy) and abortions (blighted ovum or miscarriage) was evaluated, relative to HPV status, in women who underwent IVF/IVF + ICSI $(n=161)$, IUI $(n=53)$ within 6 months after sampling or who became pregnant spontaneously $(n=46)$ within 6 months after sampling without any ART. Biochemical pregnancies (just positive hCG) were not counted as abortions. For IVF/IVF + ICSI, only embryo transfers (ETs) with one or two fresh embryos developed from the woman's own oocytes fertilized by the spermatozoa of male partner were included. 


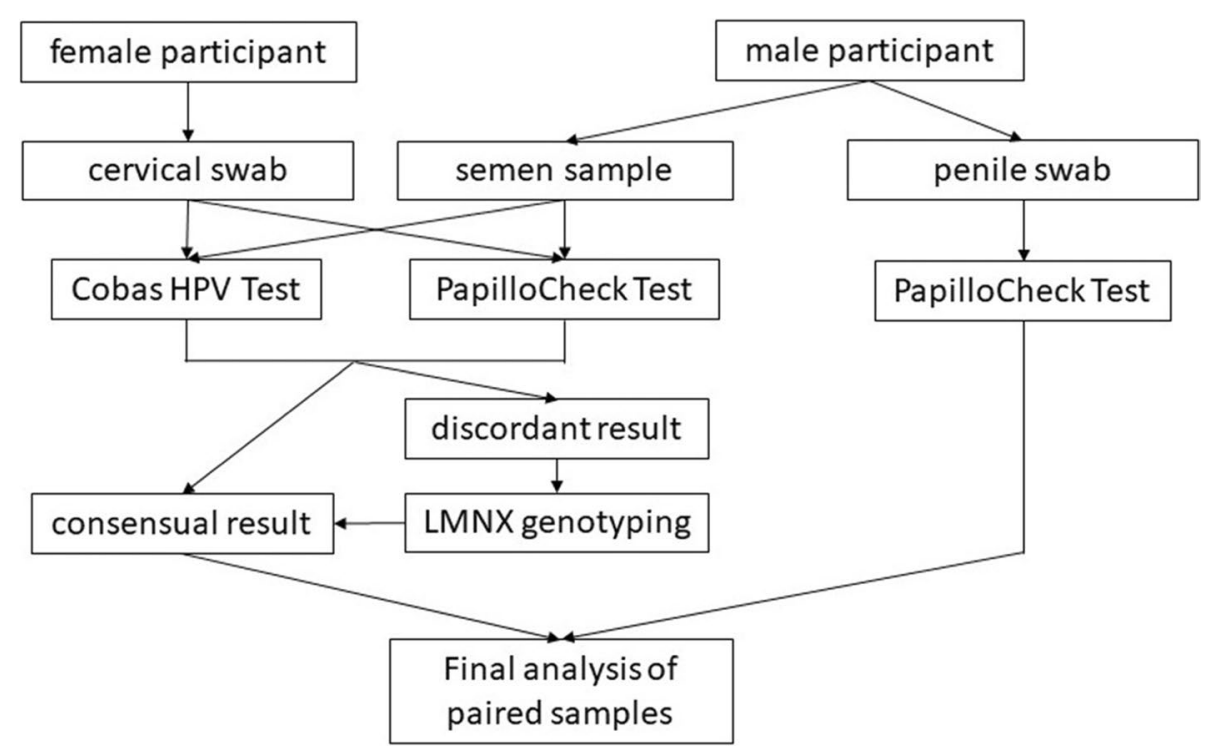

Fig. 3 Methods used for HPV detection in different sample types

\section{HPV DNA detection}

Cervical swabs and semen samples were tested for HPV DNA using the cobas ${ }^{\circledR} 4800 \mathrm{HPV}$ Test (Roche Diagnostics $\mathrm{GmBH}$, Mannheim, Germany) according to the manufacturer's recommendations for cervical sample management [17]. After analysis, DNA extracted using cobas $\times 480$ was used for HPV DNA detection and genotyping using the PapilloCheck ${ }^{\circledR}$ HPV-Screening kit (Greiner Bio-One, Frickenhausen, Germany) [18] as described previously [19]. DNA from penile swabs was isolated using the QIAamp ${ }^{\circledR}$ DNA detection by Micro kit (Qiagen, Hilden, Germany) and then tested for HPV PapilloCheck ${ }^{\circledR}$ HPV-Screening kit [18].

The cobas ${ }^{\circledR} 4800$ HPV Test and PapilloCheck ${ }^{\circledR}$ HPVScreening gave discordant results for 40 of the 425 semen samples examined in this study. These samples were further analyzed using the LMNX Genotyping Kit HPV GP (Diassay, Rijswijk, The Netherlands) [20] (Fig. 3).

\section{Other sexually transmitted diseases detection}

The presence of Chlamydia trachomatis, Ureaplasma, Mycoplasma genitalium and Mycoplasma hominis was tested in all HPV positive semen samples using the Chlamydia trachomatis/Ureaplasma/M.genitalium/M. hominis Real-TM kit (Sacace Biotechnologies, Como, Italy) [20]. DNA was extracted from a $1 \mathrm{ml}$ semen sample in cobas ${ }^{\circledR}$ PCR Cell Collection Media using QIAamp DNA Micro kit (Qiagen, Hilden, Germany) and eluted into $50 \mu \mathrm{l}$ of DEPC treated water (Sigma-Aldrich, St. Louis, USA).

\section{Statistical analysis}

The statistical software R (version 3.5.0; R Core Team, $R$ Foundation for Statistical Computing [http://www.rproject.org]) was used for data evaluation. The associations between hrHPV positivity and semen parameters, fertility outcomes, and socio-behavioral and clinical characteristics were assessed using Fisher's exact test, Pearson's chi-squared test, or the Wilcoxon exact test as appropriate. Data from questionnaires were analysed only if available. Multivariate analysis was performed using a multivariate logistic regression model with adjustment to categorized age. $P$-value $\leq 0.05$ was considered statistically significant. Only infertile couples who underwent ART within 6 months after sampling or became pregnant spontaneously within 6 months after sampling were included in the statistical analysis of fertility outcomes $(n=260)$.

\section{Results}

HPV positivity rates in potential sperm donors and men from infertile couples

The median age of men from infertile couples (IM; $n=328)$ and potential sperm donors (SD; $n=97)$ were 35 years (range, 22-62 years) and 23 years (range, 19-36years, $P<0.001$ ), respectively. We detected the DNA of at least one of $18 \mathrm{hrHPV}$ genotypes or $6 \mathrm{lrHPV}$ genotypes in $41.9 \%(178 / 425)$ of total samples, $38.1 \%$ (37/97) of SD samples, and $43.0 \%(141 / 328)$ of IM samples. HrHPV genotypes were detected in $28.9 \%(28 / 97)$ of SD samples and $35.1 \%(115 / 328)$ of IM samples 
$(P=0.312)$. LrHPV genotypes were detected in $16.5 \%$ (16/97) of SD samples and 15.2\% (50/328) of IM samples $(P=0.889)$. The most prevalent hrHPV types detected in semen samples were HPV52, HPV56 and HPV66 (2/6) in sperm donors and HPV53 (9/39) in men from infertile couples. The most prevalent hrHPV type detected in penile swabs was HPV51 (9/26) in sperm donors and HPV16 (27/106) in men from infertile couples. In couples treated for infertility the most prevalent hrHPV genotype was HPV53 (10/67) in male partner and HPV16 (14/35) in female partner.

Men with hrHPV positive penile swabs and/or semen samples from both groups had more sexual partners than those who were hrHPV negative $(P<0.001$ and $P=0.021)$. The frequency of hrHPV positive penile swabs was higher among IM who had previously had reproductive tract surgery than among IM who had not underwent any reproductive surgery $(53.8 \%$ vs. $30.4 \%$, $P=0.026)$ (Additional file 1 ).

Only 2 of the $425(0.47 \%)$ tested men were vaccinated against HPV (Cervarix or Silgard/Gardasil). One of these men was positive for HPV51 based on a penile swab. This genotype is not targeted by any vaccine.

\section{hrHPV positivity in semen samples and semen quality} IM with hrHPV positive semen samples had lower average semen volume (median volume $2 \mathrm{ml}$ vs. $3 \mathrm{ml}$, $P=0.002$ ), sperm concentration (median concentration $13 \times 10^{6} / \mathrm{ml}$ vs. $\left.26 \times 10^{6} / \mathrm{ml}, P=0.020\right)$, and total sperm count (median count $33 \times 10^{6}$ vs. $71.8 \times 10^{6}, P=0.004$ ) than those with hrHPV negative samples. No association was identified between hrHPV positivity in semen samples and semen quality in potential SD (Table 1). Among males with hrHPV positive semen samples, sperm concentrations and total sperm counts were significantly lower in IM from couples with no female factor of infertility than in sperm donors and IM from couples with a female factor of infertility $(P=0.01$ and $P=0.002$, Fig. 4). Semen quality in men with hrHPV+/ HPV+ semen sample was not affected by infection with Chlamydia trachomatis, Ureaplasma, Mycoplasma genitalium, or Mycoplasma hominis (Additional file 2). All semen parameters in SD and IM differed significantly (Additional file 3).

\section{Comparison of HPV positivity in semen samples and penile swabs}

Of the $178 \mathrm{HPV}$ positive men, 55 (30.9\%) had a positive semen sample, 169 (94.9\%) had a positive penile swab, and $46(25.8 \%)$ were positive in both samples (Table 2). Penile swabs were more frequently HPV positive than semen samples in both IM $(32.3 \%$ vs. $11.9 \%, P<0.001$ for
hrHPV; $14.9 \%$ vs. $4.88 \%$ [16/328], $P<0.001$ for $\operatorname{lrHPV})$ and SD $(26.8 \%$ vs. $6.2 \%, P=0.006$ for hrHPV; $15.5 \%$ vs. $1.03 \%, P=0.008$ for lrHPV, Table 2). There was no association found between hrHPV positivity detected in penile swabs and semen quality (Table 1 ) and between penile swabs/semen sample lrHPV infection and semen quality. Therefore, when evaluating reproductive outcomes, we focused on hrHPV detection in semen samples only.

\section{HPV positivity and fertility outcomes}

The median ages of female and male partners from infertile couples $(n=399)$ were 33 years (range: $20-45$ years) and 35 years (range: $21-44$ years), respectively. HrHPV genotypes were detected in $16.3 \%(67 / 399)$ of women and $8.77 \%(35 / 399)$ of men from infertile couples $(P=0.001)$. Both partners were hrHPV positive in $2.26 \%$ (9/399) of infertile couples. Pregnancy rates in couples treated with IVF $(98 / 161,60.9 \%)$ and couples treated with IUI $(27 / 53$, $50.9 \%)$ were comparable $(P=0.267)$. The abortion rates in spontaneously pregnant women $(5 / 46,10.9 \%)$, couples treated with IVF $(6 / 98,6.12 \%)$, and couples treated with IUI $(1 / 27,3.70 \%)$ did not differ significantly $(P=0.489)$.

No associations between hrHPV infection of male, female, or both partners and lower pregnancy rates or higher abortion rates were identified in couples treated for infertility, regardless of the method of conception (Table 3). Among infertile couples with unexplained infertility, no women with a hrHPV+ male partner became pregnant spontaneously (0/5), whereas $43.2 \%$ of women (16/37) with a hrHPV- male partner became pregnant spontaneously $(P=0.138)$. The absence of association between hrHPV positivity and fertility outcomes was confirmed by multivariate analysis (Additional files 4, 5, and 6).

\section{Discussion}

We found a high prevalence of hrHPV infection in both groups of a large study cohort comprising male partners from infertile couples and potential sperm donors, (35.1 and $28.9 \%$ ), with significantly higher hrHPV positivity in penile swabs than semen samples in both IM $(32.3 \%$ vs. $11.9 \%, P<0.001)$ and $\mathrm{SD}(26.8 \%$ vs. $6.2 \%, P=0.006)$. The hrHPV prevalence in semen samples from IM in our study cohort was lower than the pooled hrHPV prevalence reported in the meta-analysis of Laprise et al. [21] (11.9\% vs. $16 \% ; P=0.81)$, and that for SD was significantly lower $(6.2 \%$ vs. $17.4 \% ; P=0.01)$.

We demonstrated a significant association between hrHPV positive semen samples in IM and lower semen volume, sperm concentration, and total sperm count. In keeping with these findings, two previous publications reported lower sperm counts in men with positive semen 


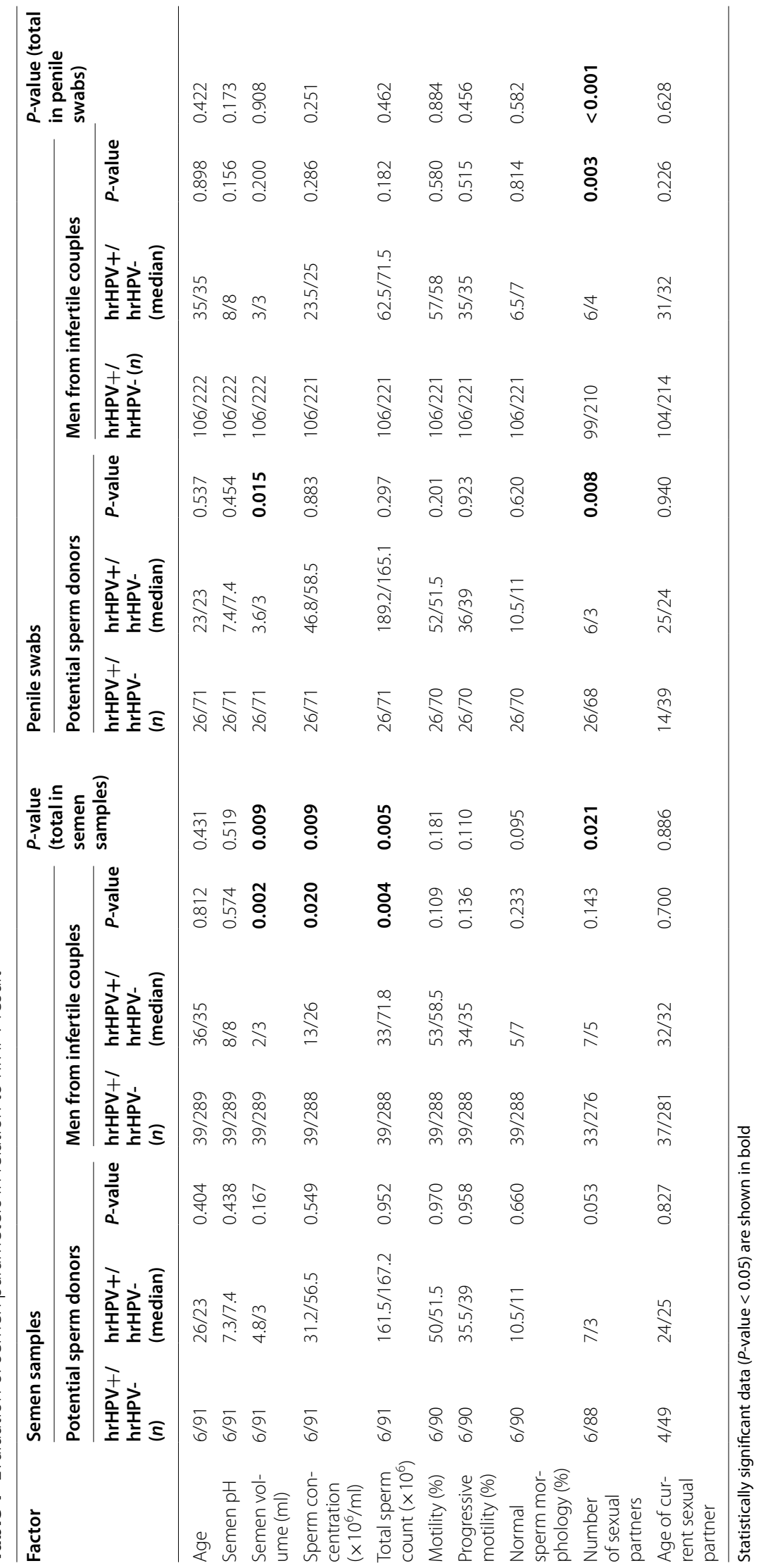



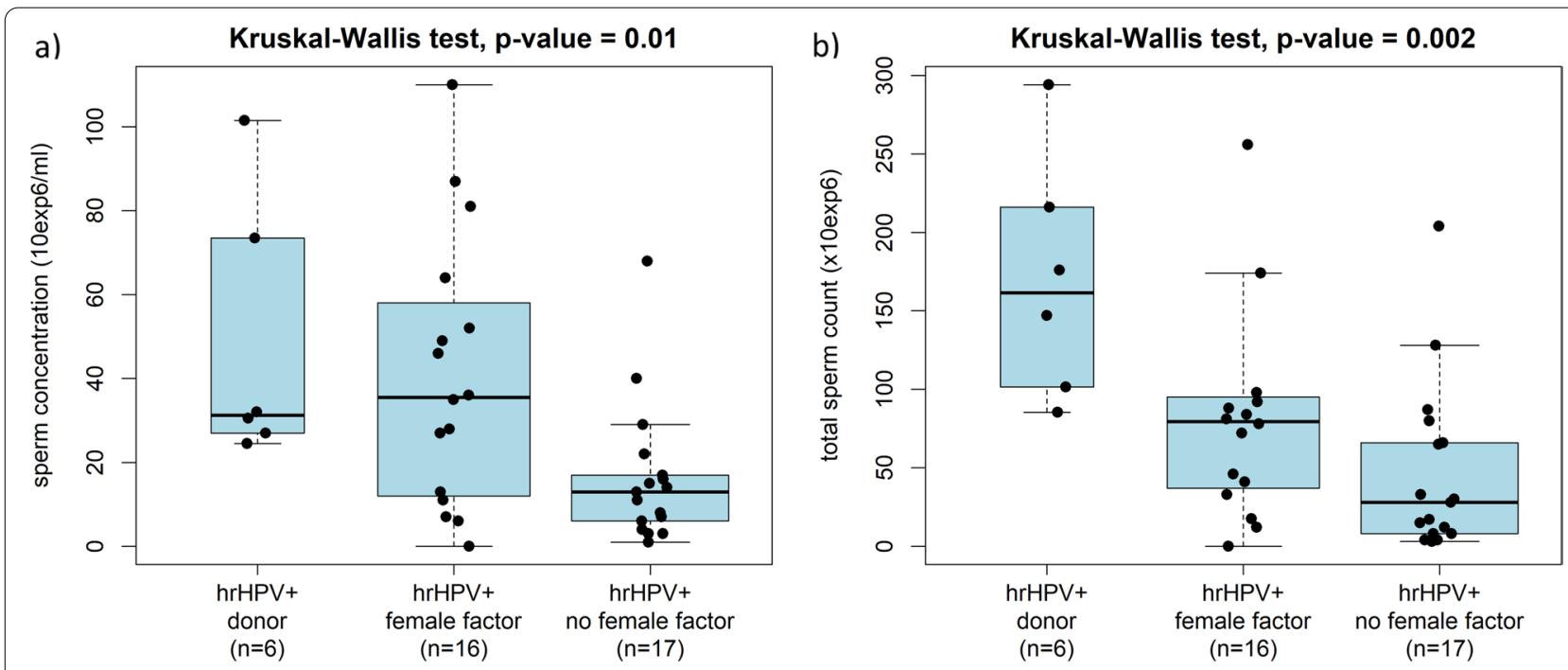

Fig. 4 Sperm concentration (a) and total sperm count (b) in men with hrHPV positive semen sample in sperm donors, men from infertile couples with female factor infertility and men from infertile couples without female factor infertility. Men with genetic factor of infertility were excluded from analysis

Table 2 Comparison of HPV positivity in semen samples and penile swabs

\begin{tabular}{|c|c|c|c|c|c|c|}
\hline & \multicolumn{2}{|c|}{ Potential sperm donors $(n=97)$} & \multicolumn{2}{|c|}{ Men from infertile couples $(n=328)$} & \multirow[t]{2}{*}{$P$-value (hrHPV) } & \multirow{2}{*}{$\begin{array}{l}P \text {-value } \\
(\text { hrHPV }+ \text { IrHPV) }\end{array}$} \\
\hline & hrHPV & hrHPV+IrHPV & hrHPV & hrHPV+IrHPV & & \\
\hline S+/PS+ & $4(4.12 \%)$ & $5(5.15 \%)$ & $30(9.15 \%)$ & $41(12.5 \%)$ & 0.165 & 0.063 \\
\hline S+/PS- & $2(2.06 \%)$ & $2(2.06 \%)$ & $9(2.74 \%)$ & $7(2.13 \%)$ & 0.994 & 1.000 \\
\hline S-/PS+ & $22(22.68 \%)$ & $30(30.93 \%)$ & $76(23.17 \%)$ & $93(28.35 \%)$ & 1.000 & 0.716 \\
\hline S-/PS- & $69(71.13 \%)$ & $60(61.86 \%)$ & $213(64.94 \%)$ & $187(57.01 \%)$ & 0.311 & 0.464 \\
\hline
\end{tabular}

HrHPV includes HPV $16,18,31,33,35,39,45,51,52,53,56,58,59,66,68,70,73$, and 82 genotypes

LrHPV includes HPV6, 11, 40, 42, 43, 44/55

S Semen samples, PS Penile swabs

samples [22, 23]. This could be due to HPV-driven DNA fragmentation in spermatozoa, which leads to apoptosis $[24,25]$. In several studies, HPV semen infection was found to be associated with significantly lower sperm motility $[8,22,24,26-30]$ due to an increase in the number of anti-sperm antibodies binding on the sperm surface $[27,28]$. Reduced motility in men with HPV positive semen samples was also observed in this study, but the association was not statistically significant $(P=0.109)$.

In vitro experiments showed that binding of HPV to sperm head affects sperm parameters, reduces the penetration rate of HPV positive sperm, and could also transfer HPV virions to the oocyte [9] and induce stagespecific maturation arrest and apoptosis in HPV-infected embryos [31]. To date, Garolla et al. [28] have reported significantly reduced spontaneous pregnancy rates in infertile couples without known infertility factors (HPV+ vs. HPV-, $0 \%$ vs. $8.1 \%, P=0.04$ ) [28]. Similarly, Depuydt et al. showed reduced clinical pregnancy rates in women receiving inseminations with HPV positive semen [32, 33]. Our results indicated that semen HPV positivity in men from infertile couples with unexplained infertility was associated with a reduced pregnancy rate, but the difference was not statistically significant (HPV+ vs. HPV-, $0 \%$ vs. $43.2 \%, P=0.138$ ). This could have been caused by relatively few couples with unexplained infertility $(n=42)$ in the group without ART treatment.

Garolla et al. [28] also reported that HPV positivity in the male partner reduced ART success rate in both IUI (HPV+ vs. HPV-, $9.5 \%$ vs. $20 \%, P=0.449)$ and ISCI (HPV+ vs. HPV-, $18.2 \%$ vs. $40.8 \%, P=0.032$ ) [28]. A similar correlation between reduced pregnancy rates and HPV DNA positivity in semen samples from male partners in infertile couples treated by IVF was reported by 


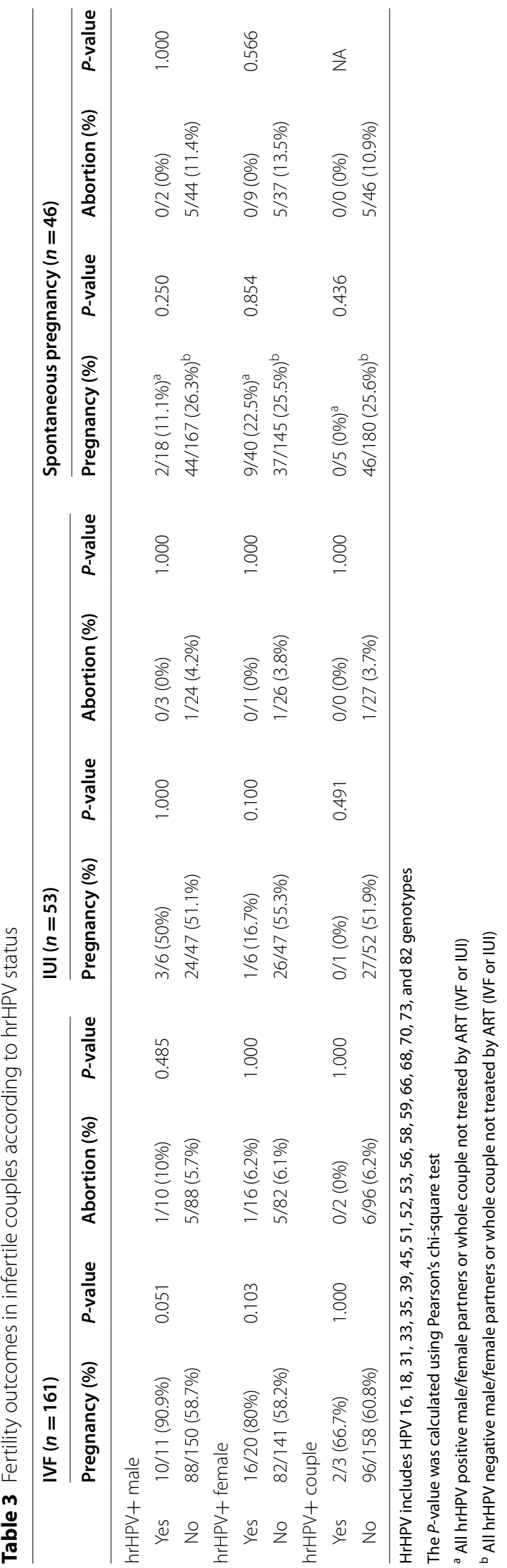


Perino et al. [15] (66.7 vs. 15\%, $P<0.01$ ). We found no association between HPV DNA positivity in semen samples and reduced ART success rates, which could be due to the small number of couples using ART in the groups with unexplained infertility. Moreover, we observed no significant association between HPV positivity in the female partner or both partners of infertile couples and reduced pregnancy rates.

An in vitro study indicated that HPV could negatively influence early embryo development, which could increase abortion rates in ART-treated couples where the male partner is HPV positive [9]. This conclusion was supported by the results of two clinical studies $[15,28]$ in which infertile couples with a HPV positive male partner had higher abortion rates than those with a HPV negative male partner $(62.5 \%$ [5/8] vs. $16.7 \%$ [11/66], $P<0.05$ and $66.7 \%[4 / 6]$ vs. $15 \%$ [9/60], $P<0.01)$. In our study, no association between hrHPV infection of male, female or both partners and higher abortion rate was identified in ART-treated couples or in couples with spontaneous pregnancy.

\section{Conclusions}

In conclusion, we have demonstrated a high prevalence of hrHPV infection in both potential sperm donors and men from infertile couples, with higher hrHPV prevalence in penile swabs compared to semen samples. HrHPV positivity in semen samples was significantly associated with reduction in semen parameters. Although we found no significant association between the presence of hrHPV DNA in semen and fertility outcomes, the data suggest that HPV infection influences male fertility and probably reduces spontaneous pregnancy rates. HPV infection probably does not affect the pregnancy rates after ART, nevertheless could adversely affect the success of spontaneous pregnancies.

\section{Abbreviations}

ART: Assisted reproduction treatment; HPV: Human papillomavirus; hrHPV: High risk human papillomavirus; IM: Male partners of infertile couples; ICSI: Intracytoplasmic injection; IUI: Intrauterine insemination; IVF: In vitro fertilization; SD: Potential sperm donor.

\section{Supplementary Information}

The online version contains supplementary material available at https://doi. org/10.1186/s12958-021-00840-y.

Additional file 1. Evaluation of questionnaires in relation to hrHPV results. *These two potential sperm donors underwent a circumcision. Sexually transmitted disease includes Chlamydia trachomatis, HPV, Trichomonas vaginalis, Neisseria gonorhaea, HSV, Ureaplasma, Mycoplasma and Cytomegalovirus. Statistically significant data $(P$-value $<0.05)$ are shown in bold.

Additional file 2. Other sexually transmitted infections in HPV positive semen samples. MO-microorganism.
Additional file 3. Comparison of semen parameters in potential sperm donors and in men from infertile couples. Statistically significant data $(P$-value $<0.05)$ are shown in bold.

Additional file 4. Fertility outcomes in infertile couples treated by IVF according to cause of infertility, age and hrHPV status. The $P$-value was calculated using Fisher's exact test $\left(^{*}\right)$ or multivariate logistic regression model with categorized age as adjusting factor $\left({ }^{* *}\right)$. Statistically significant data $(P$-value $<0.05)$ are shown in bold. $\mathrm{Cl}$ - confidence interval, NA- not available, OR- odds ratio.

Additional file 5. Fertility outcomes in infertile couples treated by IUI according to cause of infertility, age and hrHPV status. The $P$-value was calculated using Fisher's exact test $\left(^{*}\right)$ or multivariate logistic regression model with categorized age as adjusting factor $\left({ }^{* *}\right)$. Statistically significant data $(P$-value $<0.05)$ are shown in bold. $\mathrm{Cl}$ - confidence interval, NA- not available, OR-odds ratio.

Additional file 6 . Fertility outcomes in infertile couples in which women become pregnant spontaneously according to cause of infertility, age and hrHPV status. The $P$-value was calculated using Fisher's exact test $\left(^{*}\right)$ or multivariate logistic regression model with categorized age as adjusting factor $\left(^{* *}\right)$. Statistically significant data $(P$-value $<0.05)$ are shown in bold. $\mathrm{Cl}$ - confidence interval, NA- not available, OR- odds ratio.

\section{Acknowledgements}

The authors thank the staff of Fertimed Ltd., Olomouc and Arleta IVF Ltd., Kostelec nad Orlici. We also thank the technicians and research staff of the Institute of Molecular and Translational Medicine, Faculty of Medicine and Dentistry, Palacky University Olomouc.

\section{Authors' contributions}

HJ contributed to sample preparation, sample analysis, data analysis, and wrote the manuscript. VK contributed to manuscript preparation, supervised the analysis, and critically revised the manuscript. BZ, JB and DR recruited study subjects, participated in sample collection and provided clinical information. $\mathrm{IO}$ and JB recruited study subjects and controls. JV and PK performed the statistical analysis. $\mathrm{MH}$ and $\mathrm{IO}$ conceptualized and designed the study, supervised the analysis, critically revised the manuscript, edited the paper, and gave final approval. All authors read and approved the final manuscript.

\section{Funding}

Internal Grant Agency of Palacky University (IGA_LF_2021_019), Ministry of School, Education and Youth (LM2018133), Technology Agency of the Czech Republic (TN01000013), charity Cancer Research Czech Republic and European Regional Development Fund-Project ENOCH (No. CZ.02.1.01/0.0/0.0/16_019/0000868).

\section{Availability of data and materials}

The datasets used and analyzed during the current study are available from the corresponding author on reasonable request.

\section{Declarations}

\section{Ethics approval and consent to participate}

The study proposal was approved by the Ethics Committee of the Faculty of Medicine and Dentistry of Palacky University and the University Hospital Olomouc (protocol no. 29/13), in accordance with the Helsinki Declaration. All study participants provided signed informed consent for the use of their collected samples and completed a questionnaire on their health status and sexual behavior.

\section{Consent for publication}

Not applicable.

\section{Competing interests}

The authors declare that they have no competing interests.

\section{Author details}

${ }^{1}$ Institute of Molecular and Translational Medicine, Faculty of Medicine and Dentistry, Palacky University Olomouc, Hnevotinska 1333/5, 779 
00 Olomouc, Czech Republic. ${ }^{2}$ Fertimed Ltd., Boleslavova 2, 77600 Olomouc, Czech Republic. ${ }^{3}$ SpermBank International, Katerinska 13, 77900 Olomouc, Czech Republic. ${ }^{4}$ Arleta IVF Ltd., Komenskeho 702, 51741 Kostelec nad Orlici, Czech Republic.

Received: 4 February 2021 Accepted: 28 September 2021 Published online: 09 October 2021

\section{References}

1. Forman D, de Martel C, Lacey CJ, Soerjomataram I, Lortet-Tieulent J, Bruni L, et al. Global burden of human papillomavirus and related diseases. Vaccine. 2012;30(Suppl 5):F12-23. https://doi.org/10.1016/j.vaccine.2012.07.055.

2. Schiller JT, Lowy DR. Understanding and learning from the success of prophylactic human papillomavirus vaccines. Nat Rev Microbiol. 2012;10(10):681-92. https://doi.org/10.1038/nrmicro2872.

3. Souho T, Benlemlih M, Bennani B. Human papillomavirus infection and fertility alteration: a systematic review. PLoS One. 2015;10(5):e0126936. https://doi.org/10.1371/journal.pone.0126936.

4. Dunne EF, Nielson CM, Stone KM, Markowitz LE, Giuliano AR. Prevalence of HPV infection among men: a systematic review of the literature. Infect Dis. 2006;194(8):1044-57. https://doi.org/10.1086/507432.

5. Nielson CM, Flores R, Harris RB, Abrahamsen M, Papenfuss MR, Dunne $E F$, et al. Human papillomavirus prevalence and type distribution in male anogenital sites and semen. Cancer Epidemiol Biomark Prev. 2007;16(6):1107-14. https://doi.org/10.1158/1055-9965.EPI-06-0997.

6. Giovannelli L, Bellavia C, Capra G, Migliore MC, Caleca M, Giglio M, et al. HPV group- and type-specific concordance in HPV infected sexual couples. J Med Virol. 2007;79(12):1882-8. https://doi.org/10.1002/jmv.21015

7. de Lima Rocha MG, Faria FL, Gonçalves L, Souza MC, Fernandes PA, Fernandes AP. Prevalence of DNA-HPV in male sexual partners of HPVinfected women and concordance of viral types in infected couples. PLoS One. 2012;7(7):e40988. https://doi.org/10.1371/journal.pone.0040988.

8. Foresta C, Garolla A, Zuccarello D, Pizzol D, Moretti A, Barzon L, et al. Human papillomavirus found in sperm head of young adult males affects the progressive motility. Fertil Steril. 2010;93(3):802-6. https://doi.org/10. 1016/j.fertnstert.2008.10.050.

9. Foresta C, Patassini C, Bertoldo A, Menegazzo M, Francavilla F, Barzon L, et al. Mechanism of human papillomavirus binding to human spermatozoa and fertilizing ability of infected spermatozoa. PLoS One. 2011;6(3):e15036. https://doi.org/10.1371/journal.pone.0015036.

10. Foresta C, Noventa M, De Toni L, Gizzo S, Garolla A. HPV-DNA sperm infection and infertility: from a systematic literature review to a possible clinical management proposal. Andrology. 2015;3(2):163-73. https://doi. org/10.1111/andr.284

11. Hong LJ, Oshiro BT, Chan PJ. HPV-16 exposed mouse embryos: a potential model for pregnancy wastage. Arch Gynecol Obstet. 2013;287(6):1093-7. https://doi.org/10.1007/s00404-013-2711-5.

12. Weyn C, Vanderwinden JM, Rasschaert J, Englert Y, Fontaine V. Regulation of human papillomavirus type 16 early gene expression in trophoblastic and cervical cells. Virology. 2011;412(1):146-55. https://doi.org/10.1016/j. virol.2010.12.056

13. Dana A, Buchanan KM, Goss MA, Seminack MM, Shields KE, Korn S, et al. Pregnancy outcomes from the pregnancy registry of a human papillomavirus type 6/11/16/18 vaccine. Obstet Gynecol. 2009;114(6):1170-8. https://doi.org/10.1097/AOG.0b013e3181c2a122.

14. Spandorfer SD, Bongiovanni AM, Fasioulotis S, Rosenwaks Z, Ledger WJ, Witkin SS. Prevalence of cervical human papillomavirus in women undergoing in vitro fertilization and association with outcome. Fertil Steril. 2006;86(3):765-7. https://doi.org/10.1016/j.fertnstert.2006.01.051.

15. Perino A, Giovannelli L, Schillaci R, Ruvolo G, Fiorentino FP, Alimondi P, et al. Human papillomavirus infection in couples undergoing in vitro fertilization procedures: impact on reproductive outcomes. Fertil Steril. 2011;95(5):1845-8. https://doi.org/10.1016/j.fertnstert.2010.11.047.

16. World Health Organization. WHO laboratory manual for the examination of human semen and sperm-cervical mucus interaction. Cambridge: Cambridge University Press; 2010. https://apps.who.int/iris/bitstream/ handle/10665/44261/9789241547789_eng.pdf?sequence=1\&isAll owed $=y$. Accesed 28 Jan 2021
17. GmbH RD. Cobas ${ }^{\circledR} 4800$ HPV Test: Roche Molecular Systems Inc; 2012. https://www.accessdata.fda.gov/cdrh_docs/pdf10/p100020s017c.pdf. Accesed 28 Jan 2021

18. GmbH. PapilloCheck ${ }^{\circledR}$ high-risk: Greiner Bio-One; 2012. https://www.gbo. com/fileadmin/user_upload/Downloads/IFU_Instructions_for_Use/IFU_ Diagnostics/PapilloCheck/IFU_PapilloCheck_E_BQ-013-09.pdf. Accesed 28 Jan 2021

19. Jaworek H, Koudelakova V, Drabek J, Vrbkova J, Zborilova B, Oborna I, et al. A head-to-head analytical comparison of Cobas 4800 HPV, PapilloCheck HPV Screening, and LMNX Genotyping Kit HPV GP for detection of human papillomavirus DNA in cervical and cervicovaginal swabs. J Mol Diagn. 2018;20(6):849-58. https://doi.org/10.1016/j.jmoldx.2018.07.004.

20. Srl. Chlamydia trachomatis/Ureaplasma/M.genitalium/M.hominis RealTM. Sacace Biotechnologies; 2011. https://sacace.com/manuals.htm. Accesed 28 Jan 2021.

21. Laprise C, Trottier H, Monnier P, Coutlée F, Mayrand MH. Prevalence of human papillomaviruses in semen: a systematic review and meta-analysis. Hum Reprod. 2014;29(4):640-51. https://doi.org/10.1093/humrep/ det453.

22. Foresta C, Pizzol D, Moretti A, Barzon L, Palù G, Garolla A. Clinical and prognostic significance of human papillomavirus DNA in the sperm or exfoliated cells of infertile patients and subjects with risk factors. Fertil Steril. 2010;94(5):1723-7. https://doi.org/10.1016/j.fertnstert.2009.11.012.

23. Bezold G, Politch JA, Kiviat NB, Kuypers JM, Wolff H, Anderson DJ. Prevalence of sexually transmissible pathogens in semen from asymptomatic male infertility patients with and without leukocytospermia. Fertil Steril. 2007:87(5):1087-97. https://doi.org/10.1016/j.fertnstert.2006.08.109.

24. Lee CA, Huang CT, King A, Chan PJ. Differential effects of human papillomavirus DNA types on p53 tumor-suppressor gene apoptosis in sperm. Gynecol Oncol. 2002;85(3):511-6. https://doi.org/10.1006/gyno.2002. 6662.

25. Connelly DA, Chan PJ, Patton WC, King A. Human sperm deoxyribonucleic acid fragmentation by specific types of papillomavirus. Am J Obstet Gynecol. 2001;184(6):1068-70. https://doi.org/10.1067/mob.2001.115226.

26. Yang Y, Jia C-W, Ma Y-M, Zhou L-Y, Wang S-Y. Correlation between HPV sperm infection and male infertility. Asian J Androl. 2013;15(4):529-32. https://doi.org/10.1038/aja.2013.36.

27. Garolla A, Pizzol D, Bertoldo A, De Toni L, Barzon L, Foresta C. Association, prevalence, and clearance of human papillomavirus and antisperm antibodies in infected semen samples from infertile patients. Fertil Steril. 2013;99(1):125-31. https://doi.org/10.1016/j.fertnstert.2012.09.006.

28. Garolla A, Engl B, Pizzol D, Ghezzi M, Bertoldo A, Bottacin A, et al. Spontaneous fertility and in vitro fertilization outcome: new evidence of human papillomavirus sperm infection. Fertil Steril. 2016;105(1):65-72. https:// doi.org/10.1016/j.fertnstert.2015.09.018.

29. Boeri L, Capogrosso P, Ventimiglia E, Pederzoli F, Cazzaniga W, Chierigo F, et al. High-risk human papillomavirus in semen is associated with poor sperm progressive motility and a high sperm DNA fragmentation index in infertile men. Hum Reprod. 2019;34(2):209-17. https://doi.org/10.1093/ humrep/dey348.

30. Zacharis K, Messini Cl, Anifandis G, Koukoulis G, Satra M, Daponte A. Spontaneous fertility and in vitro fertilization outcome: new evidence of human papillomavirus sperm infection. Medicina. 2018;54(4):50. https:// doi.org/10.3390/medicina54040050.

31. Henneberg AA, Patton WC, Jacobson JD, Chan PJ. Human papilloma virus DNA exposure and embryo survival is stage-specific. J Assist Reprod Genet. 2006;23(6):255-9. https://doi.org/10.1007/s10815-006-9030-8.

32. Depuydt CE, Donders G, Verstraete L, Vanden Broeck D, Beert JFA, Salembier G, et al. Time has come to include Human Papillomavirus (HPV) testing in sperm donor banks. Facts Views Vis Obgyn. 2018;10(4):201-5.

33. Depuydt CE, Donders G, Verstraete L, Vanden Broeck D, Beert JFA, Salembier $\mathrm{G}$, et al. Infectious human papillomavirus virions in semen reduce clinical pregnancy rates in women undergoing intrauterine insemination. Fertil Steril. 2019;111(6):1135-44. https://doi.org/10.1016/j.fertnstert.2019. 02.002 .

\section{Publisher's Note}

Springer Nature remains neutral with regard to jurisdictional claims in published maps and institutional affiliations. 